\title{
Some factors affecting cerebral tissue saturation during obstructive sleep apnoea
}

\author{
A. Valipour*,, A.D. McGown*, H. Makker*, C. O'Sullivan\#, S.G. Spiro*
}

Some factors affecting cerebral tissue saturation during obstructive sleep apnoea. A. Valipour, A.D. McGown, H. Makker, C. O'Sullivan, S.G. Spiro. C ERS Journals Ltd 2002

ABSTRACT: Measurement of cerebral tissue saturation during obstructive sleep apnoea (OSA) may provide additional information to conventional peripheral oxygen saturation.

Thirteen subjects with OSA (mean apnoea/hypopnoea index 65.7 \pm 27.9 ) were monitored using full polysomnography and monitoring of near-infrared cerebral tissue oxygenation index (TOI). One-thousand and thirty-six apnoeas and hypopnoeas were analysed, in terms of duration, sleep stage, arterial oxygen saturation $\left(\mathrm{S}_{\mathrm{a}}, \mathrm{O}_{2}\right)$ dip, minimum $S_{\mathrm{a}, O_{2}}$, TOI dip and minimum TOI. Cerebral TOI is a measure of cerebral tissue saturation of haemoglobin with oxygen, calculated using near-infrared spatially resolved spectroscopy, which has been shown to have a high specificity for intracranial changes.

Decreases in cerebral oxygenation were observed during apnoeas and hypopnoeas. Baseline TOI ranged from 50.1-73.0\% and mean apnoea/hypopnoea related TOI dips ranged from $1.43-6.85 \%$. Mean $S_{\mathrm{a}, \mathrm{O}_{2}}$ dips varied from $3.8-21.7 \%$. In regression analysis, factors significantly predicting the magnitude of the TOI dip were $S_{a}, O_{2}$ dip, minimum $S_{a}, O_{2}$, apnoea duration and rapid eye movement sleep stage. The effect of apnoea duration and sleep stage remained significant after $S_{\mathbf{a}}, O_{2}$ was included in the regression equation.

Near-infrared spectroscopy provides a noninvasive technique for monitoring cerebral tissue saturation during obstructive sleep apnoea.

Eur Respir J 2002; 20: 444-450.
*Dept of Thoracic Medicine and \#Dept of Research and Development, University College London Hospitals, London, UK. Dept of Pulmonary and Critical Care Medicine, Pulmonary Centre Vienna, Otto-Wagner-Spital, Vienna, Austria.

Correspondence: S.G. Spiro

Dept of Thoracic Medicine

Middlesex Hospital

Mortimer Street

London

WIN 8AA

Fax: 442076375809

E-mail: s.spiro@academic.uclh.

nthames.nhs.uk

Keywords: Near-infrared spectroscopy obstructive sleep apnoea

Received: July 312001

Accepted after revision: February 19 2002
Subjects with obstructive sleep apnoea (OSA) suffer from repetitive episodes of upper airway obstruction, terminated by arousals and in most cases accompanied by transient dips in oxygen saturation. Neuropsychological deficits including excessive daytime sleepiness, cognitive impairment and behavioural problems may be associated with OSA. These impairments are thought to be due to sleep fragmentation and hypoxia, each contributing independently [1]. However in clinical studies, the relationship between neuropsychological dysfunction and hypoxaemia in subjects with OSA has been based on measurements derived from simple peripheral pulse oximetry during sleep studies [2-4]. Oxygen delivery to the brain depends on cerebral blood flow as well as arterial saturation, and cerebral blood flow varies during OSA in response to multiple factors [5]. Hence, direct measurement of local cerebral tissue oxygenation during OSA may provide additional and more relevant information to that obtained from pulse oximetry.

Using near-infrared spectroscopy (NIRS) it is possible to continuously and noninvasively monitor cerebral oxygenation [6]. The technique is used for studies of oxygen delivery to tissue and cerebral haemodynamics in neonates [7, 8] and adult humans [9-12]. Earlier NIRS models measured only changes in haemoglobin concentration and not absolute values, therefore clinical use was restricted to monitoring trends in cerebral oxygenation, e.g. during neurosurgical procedures or cardiac surgery $[12,13]$. One previous study demonstrated changes in cerebral oxygenation during OSA [14]. These early models were also criticised because there was a significant extracranial contribution to adult measurements $[15$, 16]. More recently a new monitor has been developed, the NIRO 300 (Hamamatsu Inc., Hamamatsu, Japan), which by applying spatially resolved spectroscopy can provide an absolute value for regional cerebral tissue saturation $[17,18]$. This measurement has been clinically validated with sensitivity and specificity of 87.5 and $100 \%$ for intracranial changes in adults [19]. Using the NIRO 300, cerebral tissue oxygen saturation as well as arterial oxygen saturation $\left(S_{\mathrm{a}}, \mathrm{O}_{2}\right)$ was measured using pulse oximetry and full polysomnography in 13 subjects with OSA. The aim of this study was to evaluate the effect of hypoxia on cerebral tissue oxygenation during apnoeas and 
hypopnoeas, and to investigate some factors which have a significant effect on cerebral oxygenation during apnoeas.

\section{Methods}

\section{Subjects}

Thirteen subjects (12 males) who had previously been diagnosed with moderate-to-severe OSA (mean $4 \% \mathrm{Sa}_{\mathrm{a}} \mathrm{O}_{2}$ diprate $\left.58.9 \pm 26.4 \mathrm{~h}^{-1}\right)$ in a preliminary sleep study (Visilab Syst., Oxford, UK), participated in the study. Their mean age was 47.7 yrs (SD 9.8), mean body mass index 37.0 (SD 6.9), and no patient had a history of lung disorders, cerebral or myocardial infarction. Eight subjects had been on regular nasal continuous positive airway pressure treatment which was discontinued 2-3 days prior to the study day; and five of the subjects were treatment naive. All had daytime hypersomnolence off treatment.

The study protocol was approved by the local ethics committee of the institution.

\section{Principles of near-infrared spectroscopy}

NIRS relies on the principle that body tissue is relatively transparent to light in the near-infrared spectrum. Light transmitted across the brain is absorbed by the chromophores oxyhaemoglobin $(\mathrm{OHb})$, deoxyhaemoglobin $(\mathrm{HHb})$ and cytochrome oxidase. Knowing the absorption coefficients of these substances at specified wavelengths, the distance between the optodes and an estimate of the optical path length, changes in chromophore concentrations can be calculated using a modified Beer-Lambert method [6].

\section{Principles of near-infrared spatially resolved spectroscopy}

In addition to measuring chromophore concentration changes by a modified Beer-Lambert method, the NIRO 300 also gives an absolute regional tissue saturation measurement (tissue oxygenation index (TOI)) measured in \% oxygen saturation of haemoglobin, using spatially resolved spectroscopy [18]. Light emitted at four wavelengths by a laser is scattered by the tissue and reflected light is detected by three closely spaced photodiodes. The basic measurement made is the rate of increase of light attenuation with respect to the source detector spacing at different wavelengths (fig. 1). Using assumptions from photon diffusion theory to calculate the scattering coefficient, these measurements are converted to relative absorption coefficients and then relative concentrations of $\mathrm{OHb}$ and $\mathrm{HHb}$. TOI is given by the ratio of $\mathrm{OHb}$ to $\mathrm{OHb}+\mathrm{HHb}$. Detailed derivation of the TOI measurement is given in reference [18].

\section{Study protocol}

The subjects underwent standard polysomnography (S-Series V4; Compumedics Ltd, Victoria, Australia)

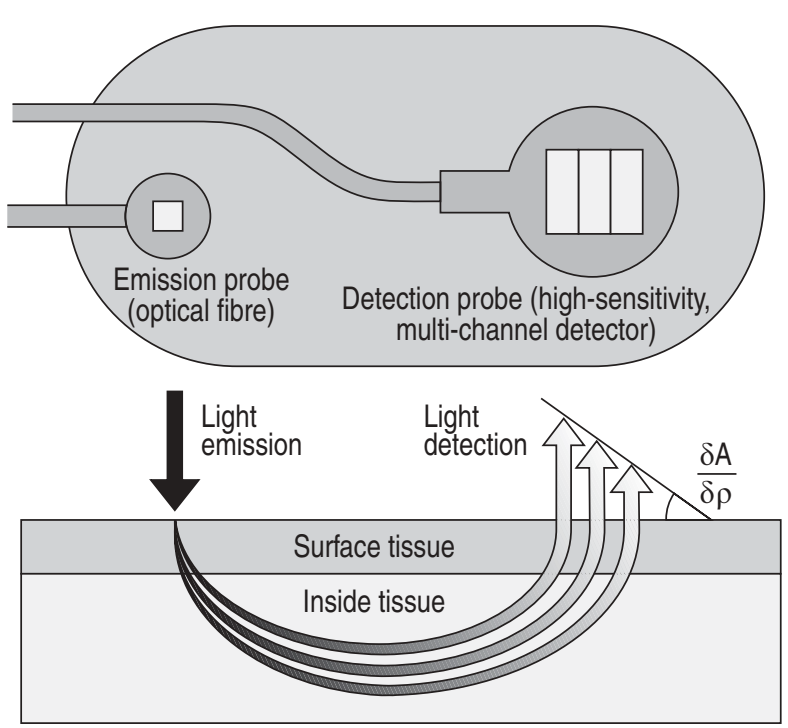

Fig. 1.-Principle of spatially resolved spectroscopy in the NIRO 300. $\delta \mathrm{A} / \delta \rho$ : rate of light attenuation over distance.

with simultaneous cerebral oxygen monitoring during spontaneous daytime sleep. Obstructive apnoeas were defined as the cessation of airflow for $>10 \mathrm{~s}$ in the presence of paradoxical movements of the rib cage and abdomen [20]. Hypopnoeas were defined as a $>50 \%$ reduction in thoraco-abdominal movements for $\geqslant 10 \mathrm{~s}$ accompanied by either a drop in oxygen saturation of $\geqslant 4 \%$ or an arousal [21]. $\mathrm{Sa}, \mathrm{O}_{2}$ was measured by peripheral pulse oximetry (PULSEOX-7; Minolta, Osaka, Japan) using a finger probe. The averaging time constant was $5 \mathrm{~s}$ and the sampling rate of the analogue output to the polysomnography was set at $1 \mathrm{~Hz}$.

The emission and the detection probe of the NIRO 300 were placed in a holder on the left side of the forehead, held in place by a self-adhesive sticker and a headband, avoiding positions near the temporalis muscle and sinuses. Sampling frequency was set at $1 \mathrm{~Hz}$. The TOI analogue signal was fed into one of the polysomnography channels to give a simultaneous real-time display of the TOI with the other polysomnography tracings (fig. 2).

\section{Data analysis}

Sleep staging was performed manually. Central apnoeas were excluded from the analysis. For each obstructive apnoea/hypopnoea, the lowest $\mathrm{Sa}_{\mathrm{a}} \mathrm{O}_{2}$ value (min $\left.S_{\mathrm{a}}, \mathrm{O}_{2}\right)$, the $S \mathrm{a}, \mathrm{O}_{2}$ difference from baseline $\left(\Delta S_{\mathrm{a}}, \mathrm{O}_{2}\right)$ and apnoea duration were obtained from the analysis function of the polysomnography software. The difference between the maximum baseline TOI value preceding each apnoea/hypopnoea and the TOI nadir obtained during each apnoea/hypopnoea-related oxygen desaturation was recorded for every event ( $\Delta \mathrm{TOI})$. The univariate associations between $\Delta \mathrm{TOI}$ and min $S_{\mathrm{a}, \mathrm{O}_{2}}, \Delta \mathrm{Sa}_{\mathrm{a}} \mathrm{O}_{2}$, sleep stage and apnoea duration were assessed for each subject using Pearson's correlation coefficients. A two-level regression analysis, 


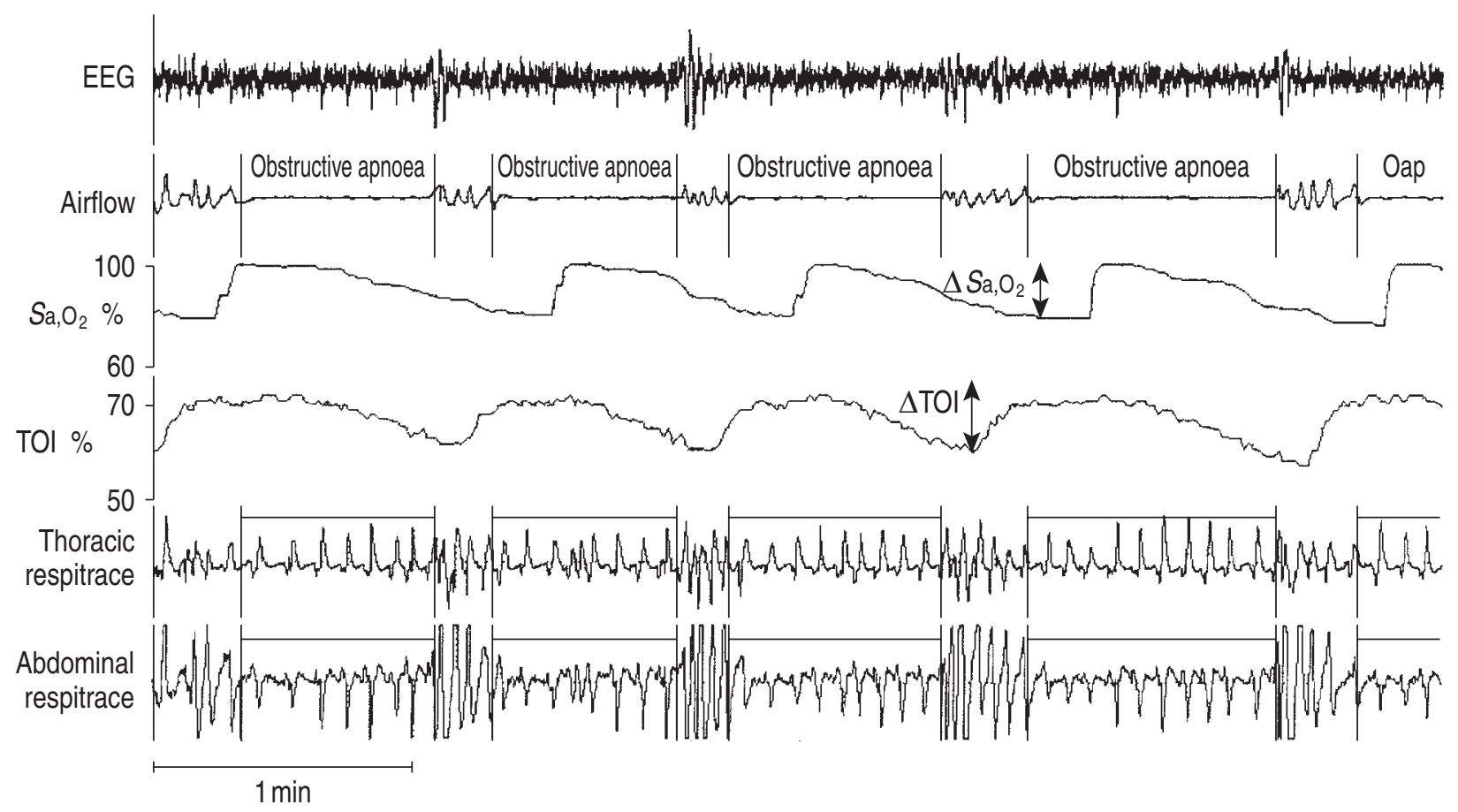

Fig. 2.-Example of polysomnography trace during repetitive apnoeas showing dips in arterial oxygen saturation $\left(S_{\mathrm{a}}, \mathrm{O}_{2}\right)$ and tissue oxygenation index (TOI) occurring in association with obstructive apnoeas. EEG: electroencephalogram.

including all 1,036 apnoeas, using possible explanatory variables that were expected to influence cerebral oxygenation (TOI), adjusting for interpatient variation, was then performed [22].

\section{Results}

Recordings were obtained during a mean sleep period of $89.9 \mathrm{~min}$ (SD 24.4) with a mean sleep latency of $2.1 \mathrm{~min}$ (SD 3.2). Slow-wave sleep was observed in eleven of the subjects and rapid eye movement (REM) sleep in four. Eleven subjects had an AHI >30 during the daytime polysomnography (table 1).
No shifts in the TOI baseline were detected during periods of relaxed wakefulness or sleep-stage transitions in nonREM sleep. The median coefficient of variation over 150 consecutive observations during unobstructed breathing in six subjects was $1.2 \%$ (range $0.7-1.4 \%$ ). In three subjects the TOI baseline was affected by major body movements, and the expected reduction in the baseline occurred during sleep in all subjects [23]. The median coefficient of variation of the TOI immediately preceding each apnoea was $2.4 \%$ (range $1.2-8.1 \%$ ) in all subjects; median $2 \%$ (range $1.2-3.5 \%$ ) in 10 subjects without baseline shift.

Baseline TOI varied from 50.2 to $75.0 \%$, where

Table 1.-Results from polysomnography and simultaneous cerebral oxygen monitoring

\begin{tabular}{lccccccc}
\hline $\begin{array}{l}\text { Patient } \\
\text { no. }\end{array}$ & $\begin{array}{c}\text { Apnoea-hypopnoea } \\
\text { index } \cdot h^{-1}\end{array}$ & $\begin{array}{c}\text { Mean minimum } \\
S_{\mathrm{a}, \mathrm{O}_{2}} \%\end{array}$ & $\begin{array}{c}\text { Mean apnoea } \\
\text { duration } \mathrm{s}\end{array}$ & $\begin{array}{c}\text { Mean } \\
\Delta \mathrm{S}_{\mathrm{a}, \mathrm{O}_{2}} \%\end{array}$ & $\begin{array}{c}\text { Mean TOI } \\
\text { baseline \% }\end{array}$ & $\begin{array}{c}\text { Mean minimum } \\
\text { TOI \% }\end{array}$ & $\begin{array}{c}\text { Mean } \\
\Delta \text { TOI \% }\end{array}$ \\
\hline 1 & 69.8 & 84.6 & 30.5 & 14.7 & 69.6 & 63.1 & 6.6 \\
2 & 94.1 & 77.9 & 25.6 & 22.3 & 57.3 & 51.4 & 5.8 \\
3 & 74.2 & 85.7 & 33.3 & 12.3 & 68.2 & 63.9 & 4.2 \\
4 & 40.4 & 87.1 & 31.5 & 11.6 & 60.6 & 53.8 & 6.8 \\
5 & 14.6 & 94.4 & 16.0 & 3.8 & 71.9 & 70.5 & 1.4 \\
6 & 59.2 & 90.4 & 25.3 & 10.1 & 50.2 & 47.6 & 2.5 \\
7 & 56.8 & 93.3 & 19.3 & 8.8 & 67.2 & 63.4 & 3.7 \\
8 & 95.2 & 87.3 & 17.2 & 7.5 & 73.0 & 69.1 & 3.9 \\
9 & 97.6 & 88.1 & 19.9 & 9.4 & 71.3 & 66.3 & 4.9 \\
10 & 96.1 & 81.7 & 19.9 & 17.0 & 58.1 & 53.0 & 5.2 \\
11 & 27.2 & 95.9 & 21.6 & 4.9 & 68.0 & 66.2 & 1.8 \\
12 & 44.0 & 83.4 & 25.7 & 10.8 & 67.9 & 61.8 & 6.2 \\
13 & 84.9 & 89.7 & 14.1 & 6.2 & 56.4 & 53.0 & 3.4 \\
Mean & 65.7 & 87.65 & 23.07 & 10.72 & 64.59 & 60.24 & 4.34 \\
SD & 27.9 & 5.1 & 6.1 & 5.1 & 7.2 & 7.5 & 1.8 \\
\hline
\end{tabular}

$\mathrm{Sa}_{\mathrm{a}} \mathrm{O}_{2}$ : arterial oxygen saturation; TOI: tissue oxygenation index. 
Table 2. - Correlation coefficients of $\Delta$ tissue oxygenation index with minimum arterial oxygen saturation $\left(\mathrm{Sa}, \mathrm{O}_{2}\right)$, $\Delta \mathrm{Sa}, \mathrm{O}_{2}$ and duration of apnoea/hypopnoea

\begin{tabular}{|c|c|c|c|c|}
\hline $\begin{array}{l}\text { Patient } \\
\text { no. }\end{array}$ & $\begin{array}{l}\text { Number } \\
\text { of apnoeas }\end{array}$ & $\underset{\mathrm{Sa}_{\mathrm{a}, \mathrm{O}_{2}}}{\operatorname{Minimum}}$ & $\Delta S_{\mathrm{a}, \mathrm{O}_{2}}$ & $\begin{array}{c}\text { Duration of } \\
\text { apnoea/hypopnoea }\end{array}$ \\
\hline 1 & 130 & $-0.875^{* *}$ & $0.889 * *$ & $0.840 * *$ \\
\hline 2 & 173 & $-0.867 * *$ & $0.863 * *$ & $0.726 * *$ \\
\hline 3 & 48 & $-0.794^{* *}$ & $0.884 * *$ & $0.713^{* *}$ \\
\hline 4 & 17 & $-0.613^{* *}$ & $0.728 * *$ & $0.612 * *$ \\
\hline 5 & 15 & $-0.608^{*}$ & $0.568 *$ & 0.317 \\
\hline 6 & 80 & $-0.608 * *$ & $0.548 * *$ & $0.483^{* *}$ \\
\hline 7 & 32 & $-0.581 * *$ & $0.689 * *$ & $0.764 * *$ \\
\hline 8 & 125 & $-0.537 * *$ & $0.500 * *$ & $0.274 * *$ \\
\hline 9 & 103 & $-0.545^{* *}$ & $0.487 * *$ & 0.130 \\
\hline 10 & 110 & $-0.525 * *$ & $0.448 * *$ & $0.778 * *$ \\
\hline 11 & 27 & $-0.461^{*}$ & $0.536 * *$ & 0.364 \\
\hline 12 & 71 & $-0.385 * *$ & $0.628 * *$ & $0.362 * *$ \\
\hline 13 & 108 & -0.160 & $0.290 * *$ & $0.276^{* *}$ \\
\hline
\end{tabular}

$*: \mathrm{p}<0.05 ; * *: \mathrm{p}<0.01$.

awake baseline $\mathrm{Sa}_{\mathrm{a}} \mathrm{O}_{2}$ was $\geqslant 94$ in all subjects. Repetitive dips in TOI were observed during successive apnoeas/hypopnoeas (fig. 2). There was a time lag of approximately $20 \mathrm{~s}$ between the $\mathrm{Sa}, \mathrm{O}_{2}$ (measured from a pulse oximeter using a finger probe) and TOI dips. The TOI and $\mathrm{Sa}_{\mathrm{a}} \mathrm{O}_{2}$ nadir occurred at $9.5 \mathrm{~s}( \pm 2.8)$ and $28.7 \mathrm{~s}( \pm 5.0)$ (range 6.9-15.9 versus 24.7-38.7; $\mathrm{p}<0.001)$ after the end of an apnoea/hypopnoea.

Mean event-related dips in TOI ranged from 1.4 $6.8 \%$, where mean oxygen desaturation dips ranged from $3.8-22.3 \%$ in the 13 subjects (table 1). Correlation coefficients between $\Delta \mathrm{TOI}$ and $\Delta \mathrm{Sa}_{\mathrm{a}} \mathrm{O}_{2}$ were significant in all subjects but ranged from 0.89-0.29. The individual correlation coefficients of $\Delta$ TOI to $\min S \mathrm{a}, \mathrm{O}_{2}, \Delta \mathrm{Sa}_{\mathrm{a}} \mathrm{O}_{2}$ and duration of apnoea/hypopnoea are presented in table 2 . A total of 50 apnoeas were recorded and analysed during REM sleep. Changes in TOI, $S \mathrm{a}_{2} \mathrm{O}_{2}$ and apnoea duration during REM sleep were significantly greater than in nonREM sleep (table 3).
In a two-level regression analysis including all apnoeas the following factors were associated significantly with the magnitude of the fall in cerebral oxygen saturation associated with an apnoea, corrected for interpatient differences: $\min \mathrm{Sa}_{2} \mathrm{O}_{2}, \Delta \mathrm{Sa}_{\mathrm{a}} \mathrm{O}_{2}$, apnoea duration and REM sleep stage (table 4). The minimum TOI reached during an apnoea was significantly predicted by min $\mathrm{Sa}_{\mathrm{a}} \mathrm{O}_{2}$ and REM sleep stage, with apnoea duration being of borderline significance (table 4).

\section{Discussion}

In these 13 subjects with moderate-to-severe OSA a reduction in regional cerebral TOI during each obstructive apnoea and hypopnoea was observed. The magnitude of the drop in cerebral tissue saturation during an obstructive event was related significantly to peripheral $\mathrm{Sa}_{\mathrm{a}} \mathrm{O}_{2}$ drop, but independently of this association, longer apnoeas and apnoeas occurring during REM sleep were also associated with greater drops in TOI. There was considerable variation between individuals in the change in TOI which occurred in response to a given saturation change. This is the first study to provide absolute values for cerebral saturation changes in subjects with sleep apnoea and to relate peripheral oxygen saturation changes to NIRS measured cerebral tissue saturation changes.

\section{Validation of NIRO 300 as an oximeter}

Development of the NIRO 300 was based on technology used in an earlier commercial machine, the NIRO 500, and a prototype spatially resolved spectroscope [17]. The TOI measurement has been validated against data from a blood-gas analyser in uniform media [18]. Comparison with an NIRS machine based on time-resolved spectroscopy (i.e. not

Table 3. - Nonrapid eye movement (REM) versus REM sleep apnoeas and their effect on arterial oxygen saturation $\left(\mathrm{Sa}, \mathrm{O}_{2}\right)$, duration of apnoea and cerebral oxygenation

\begin{tabular}{lcrrr}
\hline Patient no. & Minimum $\mathrm{S}_{\mathrm{a}, \mathrm{O}_{2}} \%$ & $\Delta \mathrm{Sa}_{\mathrm{a}, \mathrm{O}_{2} \%}$ & Duration s & $\Delta \mathrm{TOI} \%$ \\
\hline 1 & 82 versus 73 & 14 versus 25 & 27 versus 50 & 5 versus 14 \\
2 & 77 versus 59 & 21 versus 40 & 24 versus 42 & 5 versus 13 \\
4 & 89 versus 69 & 9 versus 29 & 30 versus 42 & 6 versus 9 \\
10 & 82 versus 73 & 17 versus 23 & 18 versus 31 & 4 versus 10 \\
\hline
\end{tabular}

TOI: tissue oxygenation index. $\mathrm{p}<0.001$ for all subjects.

Table 4. - Factors affecting apnoea-associated tissue oxygenation index (TOI) drops and minimum TOI

\begin{tabular}{lcccc}
\hline Factor & TOI drops & p-value & TOI min & p-value \\
\hline$S_{\mathrm{a}, \mathrm{O}_{2} \text { drop }}$ & $0.105(0.023-0.187)$ & 0.012 & $0.069(-0.224-0.361)$ & 0.644 \\
Min $\mathrm{a}_{\mathrm{a}, \mathrm{O}_{2}}$ & $-0.107(-0.128-0.086)$ & 0.000 & $0.328(0.046-0.611)$ & 0.023 \\
Apnoea duration & $0.092(0.036-0.149)$ & 0.001 & $-0.090(-0.180-0.001)$ & 0.052 \\
REM sleep & $2.405(1.134-3.676)$ & 0.000 & $-3.970(-7.828-0.112)$ & 0.044 \\
\hline
\end{tabular}

Data are presented as regression coefficients $\left(95 \%\right.$ confidence intervals) unless otherwise stated. $\mathrm{Sa}_{\mathrm{a}} \mathrm{O}_{2}$ : arterial oxygen saturation; REM: rapid eye movement. 
requiring assumptions about the scattering coefficient) showed excellent correlation in the human arm [18]. Spatial resolution and validation as a cerebral
oximeter

Spatial resolution of NIRS is poorly defined and the NIRO 300 is no exception. Because of light scattering in the tissue, the area imaged surrounds the intraoptode dimension to a depth of a few $\mathrm{cm}$. The penetration depth of near-infra red light depends on intraoptode spacing [24] and can be calculated using theoretical modelling to be $1.2-2 \mathrm{~cm}$ at a spacing of $2.7 \mathrm{~cm}$ [25]. Penetration into the cerebral cortex has been confirmed using dye techniques [25]. The standard left frontal probe position is chosen because of practical considerations (lack of overlying muscle, sinuses or hair). Haemoglobin imaged is therefore predominantly within the left frontal cortical microcirculation, consisting on average of $75 \%$ venous, and $25 \%$ arterial or capillary blood. Use of NIRS as a cerebral oximeter assumes that: 1) it is imaging brain and 2) the local changes in cerebral oxygenation represent global changes occurring in response to a global hypoxaemic or haemodynamic challenge.

The first of these assumptions has been challenged for other NIRS models, due to extracranial contamination [15], but in the case of the NIRO 300 an intracranial origin of the signal has been confirmed in patients undergoing carotid endarterectomy [19]. Using sequential clamping of internal and external carotids in 60 patients during carotid surgery, TOI changes were seen in 49 subjects; during external carotid clamping in eight, and during internal carotid clamping in 41. TOI correlated significantly with cerebral blood-flow velocity $(r=0.56)$ but not with cutaneous laser-Doppler flowmetry $(r=0.13)$. Discounting the eight subjects in whom clamping the external carotid affected systemic blood pressure and cerebral blood flow velocity (CBFV), the sensitivity of TOI to intracranial and extracranial changes was 87.5 and $0 \%$ respectively, and specificity was 100 and $0 \%$, respectively [19].

Further support for the origin of signals from cerebral cortex has come from functional imaging studies. A study using the NIRO 500 showed haemodynamic alterations accompanying brain activation during cognitive testing in 10 subjects with optodes in the left frontal position [26]. Laser Doppler was used to show that the findings were not due to changes in skin blood flow.

The second assumption, that local changes are representative of global changes, holds provided that the subjects have no focal cerebral disease, and that there is no focal stimulation of parts of the cortex. The subjects in this study had no history of cerebrovascular disease. As changes in TOI during individual apnoeas were measured from a moving baseline, any regional changes in cerebral blood flow during sleep would only affect the interpretation of the findings if they occurred on a timescale of individual apnoeas. Regional abnormalities in cerebral blood flow including frontal hyperperfusion have been shown in subjects during periods of apnoeas, using SPECT imaging [27]. However the time resolution of this technique is not sufficient to show whether there are regional cerebral blood flow changes during individual apnoeas.

\section{Clinical significance of tissue oxygenation index measurement}

Baseline TOI measurements are variable despite similar baseline $\mathrm{Sa}_{\mathrm{a}} \mathrm{O}_{2}$, both in this study and in 60 subjects undergoing carotid endarterectomy (mean baseline TOI 67.8\% ( $\mathrm{SD}=8.8$, range 49-93)) [19]. Cerebral oxygenation depends on cerebral blood flow as well as $\mathrm{Sa}_{\mathrm{a}} \mathrm{O}_{2}$, and the latter subjects also demonstrated a range of middle cerebral artery flow velocities. In addition the relative arterial and venous contributions to the signal vary from person to person and with site [28]. Local blood-flow variations, changes in tissue oxygen consumption and global cerebral blood-flow changes will introduce variability in the signal from one subject over time. The clinical significance of small changes in TOI is not known, although as values of haemoglobin saturation in tissues are on the steep part of the haemoglobin dissociation curve, the corresponding changes in the partial pressure of oxygen will be relatively large. Small changes in intracellular redox state may affect neurotransmitter metabolism [29]. The mean changes in TOI during apnoea in this study ranged from $1.4-6.8 \%$ (median $4.2 \%$ ). Using a similar NIRS-derived tissue saturation in subjects undergoing carotid endarterectomy under local anaesthetic, the mean saturation in 10 subjects who displayed neurological symptoms on clamping the internal carotid fell from $63.2 \pm 8.4$ to $51 \pm 11.6 \%$, compared to $65.8 \pm 8.5$ to $61.0+9.3 \%$ in 90 subjects who were symptom free [30].

\section{Practical issues}

The pattern of blood pressure and CBFV changes during individual apnoeas is similar during daytime sleep [5] and night sleep [31]. Daytime studies were chosen because of concern about possible local reactions to the emitter probe.

The time lag between $S_{\mathrm{a}}, \mathrm{O}_{2}$, and TOI readings is due to the circulation time of around $20 \mathrm{~s}$ for a finger oximeter. Circulation time varies due to blood pressure lability during apnoeas, so direct correlation of the data series was not possible. Therefore, a twopoint correlation analysis was chosen so that the findings were not affected. Ear oximetry was not used for technical reasons.

Cerebrovascular reactivity is reduced in OSA, but reverts to normal following one night of CPAP use [32]. It is not known how rapidly reactivity returns to pretreatment state on stopping CPAP use. Eight of the subjects in this study had discontinued CPAP use for 2-3 days prior to the study and if their cerebrovascular reactivity had not fully returned to the pretreatment state, cerebral oxygenation changes 
in untreated patients with OSA may be greater than those observed here.

\section{Interpretation of findings}

In the only previous study using the NIRS technique in OSA, a decrease in oxygenated haemoglobin and an increase in deoxygenated haemoglobin concentrations during periods of sleep apnoea was reported, as well as changes in cerebral blood volume during each apnoea [14]. The increased cerebral blood volume did not fully compensate for the reduction in arterial $\mathrm{Sa}_{\mathrm{a}, \mathrm{O}_{2}}$. The NIRO 300 has two main advantages over the machine previously used. First, spatially resolved spectroscopy allows quantification of an absolute tissue saturation, so is not restricted to measurements of relative change. Secondly, by subtracting measurements at different distances the algorithm used in the NIRO 300 selects for intracranial signal, eliminating the contribution of extracranial skin and muscle to the signal obtained [18, 19]. Therefore, cerebral tissue saturation changes could be quantified during apnoea and these changes could be related to arterial oxygen saturation and other physiological parameters of sleep studies.

Apnoea duration and REM sleep stage are known to affect the extent of oxygen desaturation in OSA [33-35], but independently of $\mathrm{Sa}_{\mathrm{a}} \mathrm{O}_{2}$, they also have a significant association with the magnitude of the TOI drop in the regression model (table 4). Cerebral blood flow is initially reduced during obstructive apnoea, due to intrathoracic negative pressure, and then increases because of changes in first partial pressure of carbon dioxide and then arterial blood pressure [5, 32, 36, 37]. The authors postulate that longer apnoeas and apnoeas in REM sleep may be associated with greater swings in cerebral blood flow as well as larger desaturations, so that cerebral bloodflow reductions exacerbate the effect of desaturation on cerebral oxygenation. Cerebral blood flow is more likely to be reduced in longer obstructive events [37], and tissue oxygen extraction may also be increased in longer apnoeas. Cerebral blood flow is increased in REM sleep [32], but this is coupled to an increase in cerebral metabolic rate and tissue oxygen extraction [38]. Monitoring of CBFV directly would have assisted the interpretation of the findings in this study.

The main interest in developing a reliable method of measuring cerebral oxygenation noninvasively during sleep lies in its potential for explaining neuropsychological deficit in subjects with OSA. Previous studies have examined the influence of isolated variables, such as baseline and min $\mathrm{Sa}_{\mathrm{a}} \mathrm{O}_{2}$, apnoea/hypopnoea index arousal frequency or number of $4 \% \mathrm{Sa}_{2} \mathrm{O}_{2}$ dips on neuropsychological deficits in OSA [39-41]. One of the reasons for poor correlation between measures of oxygen desaturation and cognitive deficit could be intracerebral compensation for peripheral desaturation. The analysis here of $>1,000$ apnoeas does not suggest that complete compensation occurs, as TOI does change during apnoeas. There is however, considerable interindividual variation in the TOI change that occurs in response to a given saturation change. Having demonstrated the feasibility of the use of this instrument in subjects with OSA, the measurement needs to be validated clinically against objective neuropsychological testing.

In conclusion, cerebral tissue saturation is closely related to arterial oxygen saturation during obstructive sleep apnoea, but other factors also contribute independently to cerebral tissue-saturation changes during apnoea. Conclusions made about cerebral oxygenation based on pulse oximetry alone, as in studies of neuropsychological function in obstructive sleep apnoea, may be missing important information about the effects of changes in cerebral blood flow and oxygen consumption which vary with sleep stage, apnoea duration and between individuals. The use of the NIRO 300 allows continuous, noninvasive dynamic monitoring of changes in cerebral tissue oxygen saturation during obstructive sleep apnoea and reveals that cerebral oxygenation changes are more complex than those inferred from peripheral pulse oximetry.

Acknowledgements. The authors would like to thank D. Delpy for advice, A. Chu for adaptation of the polysomnography equipment, $\mathrm{S}$. Emegbo for technical assistance with polysomnography, P. L'Estrange for suggestions and Hamamatsu Photonics K.K. for the initial loan of the equipment.

\section{References}

1. Engleman H, Joffe D. Neuropsychological function in obstructive sleep apnoea. Sleep Medicine Rev 1999; 3: $59-78$

2. Bedard M-A, Montplaisir J, Richler F, Malo J. Nocturnal hypoxemia as a determinant of vigilance impairment in sleep apnea syndrome. Chest 1991; 100: 367-370.

3. Cheshire K, Engleman H, Deary I, Shapiro C, Douglas NJ. Factors impairing daytime performance in patients with sleep apnea/hypopnea syndrome. Arch Intern Med 1992; 152: 538-541.

4. Findley LJ, Barth JT, Powers DC, Wilhoit SC, Boyd DG, Suratt PM. Cognitive impairment in patients with obstructive sleep apnea and associated hypoxemia. Chest 1986; 1986: 686-690.

5. Balfors EM, Franklin KA. Impairment of cerebral perfusion during obstructive sleep apneas. Am J Respir Crit Care Med 1994; 150: 1587-1591.

6. Elwell CE. A practical users guide to near-infrared spectroscopy. Hamamatsu, Japan, Hamamatsu Photonics KK, 1995.

7. Wyatt JS, Cope M, Delpy DT, Wray S, Reynolds EOR. Quantification of cerebral oxygenation and haemodynamics in sick newborn infants by near infrared spectrophotometry. Lancet: 1986: 1063-1066.

8. Brazy JE, Lewis DV, Mitnick MH, Joebsis FF. Noninvasive monitoring of cerebral oxygenation in preterm infants, preliminary observations. Pediatrics 1985; 75: 217-225.

9. Hampson NB, Camporesi EM, Stolp BW, et al. Cerebral oxygen availability by NIR spectroscopy 
during transient hypoxia in humans. J Appl Physiol 1990; 69: 907-913.

10. Kirkpatrick PJ. Use of near-infrared spectroscopy in the adult. Philos Trans R Soc Lord B Biol Sci 1997; 352: 701-705.

11. Lovell AT, Owen-Reece H, Elwell CE, Smith M, Goldstone JC. Continuous measurement of cerebral oxygenation by near infrared spectroscopy during induction of anesthesia. Anesth Analg 1999; 88: 554 558.

12. Nollert G, Mohnle P, Tassani-Prell P, et al. Postoperative neuropsychological dysfunction and cerebral oxygenation during cardiac surgery. Thorac Cardiovasc Surgeon 1995; 43: 260-264.

13. Kirkpatrick PJ, Smielewski P, Czosnyka M, Menon DK, Pickard JD. Near-infrared spectroscopy use in patients with head injury. J Neurosurg 1995; 83: 963 970.

14. Hayakawa T, Terashima M, Kayukawa Y, Ohta T, Okada T. Changes in cerebral oxygenation and hemodynamics during obstructive sleep apneas. Chest 1996; 109: 916-921.

15. Harris DN, Bailey SM. Near infrared spectroscopy in adults - does the Invos 3100 really measure intracerebral oxygenation. Anaesthesia 1993; 48: 694-696.

16. Lam JM, Smielewski P, al-Rawi P, Griffiths P, Pickard JD, Kirkpatrick PJ. Internal and external carotid contributions to near-infrared spectroscopy during carotid endarterectomy. Stroke 1997; 28: 906911.

17. Matcher SJ, Kirkpatrick P, Nahid K, Cope M, Delpy DT. Absolute quantification methods in tissue near infrared spectroscopy. Proc SPIE 1993; 2389: 486495.

18. Suzuki S, Takasaki S, Osaki T, Kobayashi Y. A tissue oxygenation monitor using NIR spatially resolved spectroscopy. Proc SPIE 1999; 3597: 582-592.

19. Al-Rawi PG, Smielewski P, Kirkpatrick PJ. Evaluation of a near infrared spectrometer (NIR0300) for the detection of intracranial oxygenation changes in the adult head. Stroke 2001; 32: 2492-2500.

20. Phillipson EA, Bowes G. Sleep disorders. In: Update: Pulmonary diseases and disorders. New York, McGraw-Hill, 1982; pp. 256-273.

21. Gould GA, Whyte KF, Rhind GB, et al. The sleep hypopnea syndrome. Am Rev Respir Dis 1988; 137: 895-898.

22. Liang K-Y, Zeger SL. Longitudinal data analysis using generalised linear models. Biometrika 1986; 73: 13-22.

23. Spielman AJ, Zhang G, Yang CM, et al. Intracerebral hemodynamics probed by near infrared spectroscopy in the transition between wakefulness and sleep. Brain Res 2000; 866: 313-325.

24. McCormick PW, Stewart M, Goetting MG, Dujovny M, Lewis G, Ausman JI. Noninvasive cerebral optical spectroscopy for monitoring cerebral oxygen delivery and hemodynamics. Crit Care Med 1991; 19: 89-97.

25. McCormick PW, Stewart M, Lewis G, Dujovny M, Ausman JI. Intracerebral penetration of infrared light. J Neurosurg 1992; 76: 315-318.
26. Villringer A, Planck J, Hock C, Schleinkofer L, Dimagl U. Near infrared spectroscopy: a new tool to study hemodynamic changes during activation of brain function in human adults. Neurosci Lett 1993; 154: 101-104.

27. Ficker $\mathrm{JH}$, Feistel $\mathrm{H}$, Moller $\mathrm{C}$, et al. Changes in regional CNS perfusion in obstructive sleep apnoea syndrome, initial SPECT studies with injected nocturnal 99mTc-HMPAO. Pneumologie 1997; 51: 926-930.

28. Watzman HM, Kurth CD, Montenegro LM, Rome J, Steven JM, Nicolson SC. Arterial and venous contributions to near-infrared cerebral oximetry. Anesthesiology 2000; 93: 947-953.

29. Gibson GE, Pulsinelli W, Blass JP, Duffy TE. Brain dysfunction in mild to moderate hypoxia. Am J Med 1981; 70: 1247-1254.

30. Samra SK, Dy EA, Welch K, Dorje P, Zelenock GB, Stanley JC. Evaluation of a cerebral oximeter as a monitor of cerebral ischemia during carotid endarterectomy. Anesthesiology 2000; 93: 964-970.

31. Hajak G, Klingelhofer J, Schulz-Varszegi M, Sander D, Ruther E. Sleep apnea syndrome and cerebral hemodynamics. Chest 1996; 110: 670-679.

32. Diomedi M, Placidi F, Cupini LM, Bernadi G, Silvestrini M. Cerebral hemodynamic changes in sleep apnea syndrome and effect of continuous positive airway pressure treatment. Neurology 1998; 51: 1051-1056.

33. Findley LJ, Wilhoit SC, Suratt PM. Apnea duration and hypoxemia during REM sleep in patients with obstructive sleep apnea. Chest 1985; 432-436.

34. Bradley TD, Martinez D, Rutherford R, et al. Physiological determinants of nocturnal arterial oxygenation in patients with obstructive sleep apnea. J Appl Phvsiol 1985; 59: 1364-1368.

35. Fletcher EC, Goodnight-White S, Munafo D, Miller CC, Luckett R, Qian W. Rate of oxyhemoglobin desaturation in obstructive versus non-obstructive apnea. Am Rev Respir Dis 1991; 143: 657-660.

36. Fischer AQ, Chaudhary BA, Taormina MA, Akhtar B. Intracranial hemodynamics in sleep apnea. Chest 1992; 102: 1402-1406.

37. Netzer N, Werner P, Jochums I, Lehmann M, Strohl KP. Blood flow of the middle cerebral artery with sleep-disordered breathing: correlation with obstructive hypopneas. Stroke 1998; 29: 87-93.

38. Lenzi P, Zoccoli G, Walker AM, Franzini C. Cerebral blood flow regulation in REM sleep; a model for flow metabolism coupling. Arch Ital Biol 1999; 137: $165-179$.

39. Kotterba S, Rasche K, Widdig W, et al. Neuropsychological investigations and event-related potentials in obstructive sleep apnoea syndrome before and during CPAP therapy. J Neurol Sci 1998; 159: 45-50.

40. Kingshott RN, Engleman HM, Deary IJ, Douglas NJ. Does arousal frequency predict daytime function? Eur Respir J 1998; 12: 1264-1270.

41. Kingshott RN, Vennelle M, Hoy CJ, Engleman HM, Deary IJ, Douglas NJ. Predictors of improvements in daytime function outcomes with CPAP therapy. Am J Respir Crit Care Med 2000; 161: 866-871. 